\title{
Successful use of a ventricular assist device in a neonate with hypoplastic left heart syndrome with right ventricular dysfunction
}

\author{
Katsuhide Maeda, MD, PhD, ${ }^{\mathrm{a}}$ Vamsi V. Yarlagadda, MD, ${ }^{\mathrm{b}}$ David N. Rosenthal, MD, ${ }^{\mathrm{b}}$ and \\ Chris S. Almond, MD, ${ }^{\mathrm{b}}$ Stanford, Calif
}

\author{
From the Departments of a Cardiothoracic Surgery and ${ }^{b}$ Pediatrics, Stanford University, Stanford, Calif. \\ Disclosures: Authors have nothing to disclose with regard to commercial support. \\ No funding was provided for this work \\ Received for publication Feb 20, 2018; revisions received April 10, 2018; accepted for publication May 8, 2018; \\ available ahead of print June 30, 2018. \\ Address for reprints: Katsuhide Maeda, MD, PhD, Division of Pediatric Cardiac Surgery, Department of \\ Cardiothoracic Surgery, Stanford University Medical Center, Falk Cardiovascular Research Center, 300 Pasteur \\ Dr, Stanford, CA 94305-5407 (E-mail: kmaeda@stanford.edu). \\ J Thorac Cardiovasc Surg 2018;156:e171-3 \\ $0022-5223 / \$ 36.00$ \\ Copyright (C) 2018 by The American Association for Thoracic Surgery \\ https://doi.org/10.1016/j.jtcvs.2018.05.043
}

Neonates with hypoplastic left heart syndrome (HLHS) and severe ventricular dysfunction are difficult to bridge to heart transplant (HT) with current mechanical support devices. ${ }^{1,2}$ In 2017, Gazit and colleagues ${ }^{3}$ described a novel approach in which the PediMag device (Thoratec Corporation, Pleasanton, Calif) and Berlin Heart cannulas (Berlin Heart $\mathrm{GmbH}$, Berlin, Germany) were used to support a neonate with HLHS. Although the patient was supported for 35 days, the patient did not survive to transplant because of progressive pulmonary vein disease. We present the case of a neonate with HLHS and severe ventricular dysfunction supported successfully to HT and discuss the lessons that we learned from our experience.

\section{CASE}

A term $3.5-\mathrm{kg}$ male infant had a postnatal diagnosis of HLHS and severe right ventricular dysfunction after presenting in cardiogenic shock treated with a prostaglandin infusion, multiple inotropes, and mechanical ventilation. Echocardiogram showed mitral stenosis and aortic stenosis, a dilated right ventricle with severe dysfunction, and mild to moderate tricuspid regurgitation. On day of life 3, the patient underwent bilateral pulmonary artery banding. His cardiac function remained poor, precluding weaning of support, so a decision was made to implant the Thoratec PediMag temporary circulatory support device as a bridge to HT.

\section{PediMag Placement Off Pump}

After reopening the chest, and without cardiopulmonary bypass, a side-biting clamp was applied on the proximal pulmonary trunk just above the sinotubular junction. An 8-mm Hemashield Platinum Dacron graft (MAQUET Cardiovascular, LLC, Wayne, NJ) was sewn onto it with

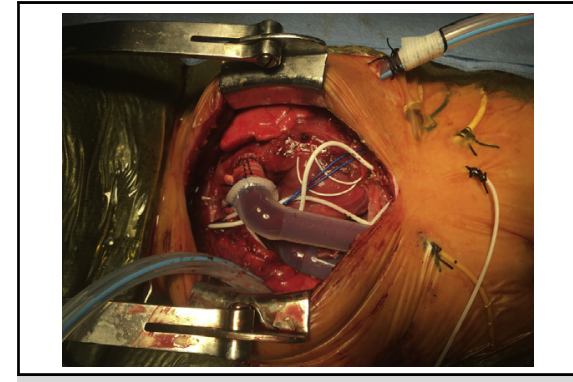

Right atrial to pulmonary trunk VAD cannulation with Berlin Heart EXCOR cannulas.

Central Message

Right atrial to pulmonary trunk temporary VAD support with Thoratec PediMag in combination with bilateral PA banding can be a viable option in children with HLHS born with depressed cardiac function.

See Editorial Commentary page e175.

7-0 Prolene running sutures (Ethicon Inc, Somerville, NJ). The graft was then connected into a 6-mm Berlin Heart EXCOR outflow cannula, which was tunneled out from the upper abdomen. For the inflow cannula, a 6-mm Berlin Heart atrial cannula was used (Figure 1). To prevent clot formation and ensure adequate flow, multiple additional

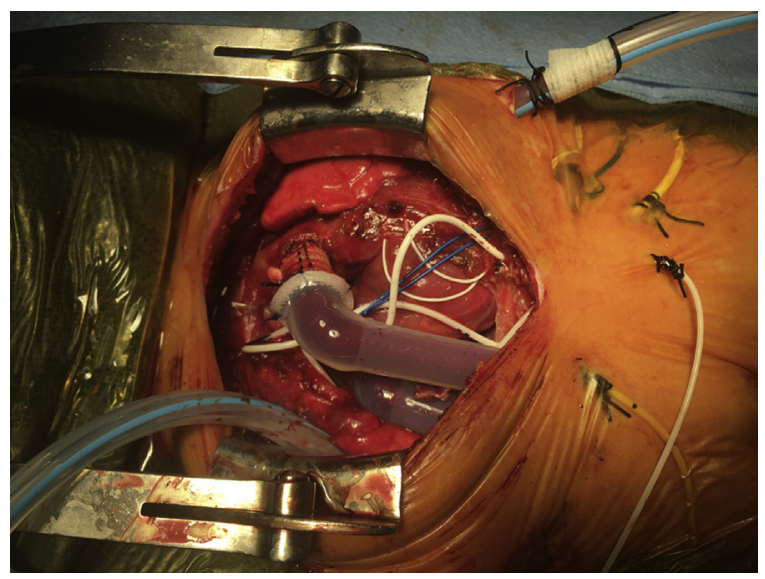

FIGURE 1. Right atrial to pulmonary trunk ventricular assist device cannulation with Berlin heart EXCOR cannulas (Berlin Heart GmbH, Berlin, Germany). 
TABLE 1. Lessons learned from problems encountered and Pedimacs-defined adverse events

\begin{tabular}{|c|c|c|}
\hline Problem & Description & Lessons learned \\
\hline $\begin{array}{l}\text { Severe hemolysis early } \\
\text { after implantation }\end{array}$ & $\begin{array}{l}\text { Frank hemoglobinuria was present, with } \mathrm{LDH} \text { peak of } \\
3740 \mathrm{U} / \mathrm{L} \text { and total bilirubin peak of } 21.4 \mathrm{mg} / \mathrm{dL} \\
\text { within } 72 \mathrm{~h} \text { of implantation. }\end{array}$ & $\begin{array}{l}\text { Although pump cylinder appears to fit snugly within } \\
\text { pump housing, it is possible for it to sit slightly } \\
\text { off-axis. Pump was replaced on postoperative day } 2 \\
\text { with proper positioning verified, with rapid resolution } \\
\text { of hemolysis. }\end{array}$ \\
\hline $\begin{array}{l}\text { Recurrent bloody stools } \\
\text { suspect for NEC }\end{array}$ & $\begin{array}{l}\text { Despite excellent pump flows and evidence of good } \\
\text { systemic perfusion, hematochezia (in absence of } \\
\text { radiographic evidence of NEC) persisted, permitting } \\
\text { only intermittent trophic feeds while on support. }\end{array}$ & $\begin{array}{l}\text { It can be difficult to be differentiate hematochezia and } \\
\text { NEC in a neonate receiving anticoagulation during } \\
\text { VAD support. Because we were unsure, and recurrent } \\
\text { bleeding could lead to stopping heparin (leaving the } \\
\text { pump unprotected), we elected to feed parenterally for } \\
\text { much of the patient's course. Despite this, the patient } \\
\text { gained weight. }\end{array}$ \\
\hline Splenic infarct & $\begin{array}{l}\text { Noted incidentally on CT of abdomen obtained to } \\
\text { evaluate NEC. }\end{array}$ & $\begin{array}{l}\text { It was difficult to determine whether this was related to } \\
\text { PediMag device because of the lack of previous CT; } \\
\text { however, it would be attributed to PediMag by most } \\
\text { adjudication processes. }\end{array}$ \\
\hline Culture-negative sepsis & $\begin{array}{l}\text { Fever, hypotension, and AKI were present in absence of } \\
\text { positive blood culture. }\end{array}$ & $\begin{array}{l}\text { Treated conservatively with broad-spectrum antibiotics, } \\
\text { antifungals, and line replacement because of presence } \\
\text { of hardware. }\end{array}$ \\
\hline $\begin{array}{l}\text { Limited mobility and } \\
\text { confinement to intensive } \\
\text { care }\end{array}$ & $\begin{array}{l}\text { We were unable to discharge the patient to floor or } \\
\text { engage in aggressive physical therapy because of } \\
\text { extracorporeal pump configuration. }\end{array}$ & $\begin{array}{l}\text { Patient was able to sit in parent's lap and feed while } \\
\text { awake and extubated. }\end{array}$ \\
\hline $\begin{array}{l}\text { Persistent venous congestion } \\
\text { complicated by AKI despite } \\
\text { VAD support }\end{array}$ & $\begin{array}{l}\text { VAD rotational speed was increased to escalate flows to } \\
\text { as high as } 1.5 \mathrm{~L} / \mathrm{min}\left(7 \mathrm{~L} / \mathrm{min} / \mathrm{m}^{2}\right) \text {, and dopamine was } \\
\text { used to maintain an adequate renal perfusion pressure } \\
\text { to clear free water. }\end{array}$ & $\begin{array}{l}\text { This is a common problem in patients with single } \\
\text { ventricle, who tend to be volume loaded. Additional } \\
\text { side holes in atrial cannula permitted escalation of } \\
\text { flows as needed to overcome. }\end{array}$ \\
\hline Pulmonary edema & $\begin{array}{l}\text { Pulmonary edema despite low central venous pressure } \\
\text { prompted cardiac catheterization and stent placement } \\
\text { in atrial septum. }\end{array}$ & $\begin{array}{l}\text { Patient may require repeated cardiac catheterizations to } \\
\text { maintain stability during wait for a donor heart. } \\
\text { Weekly echocardiographic surveillance of hybrid } \\
\text { circulation is required to allow early intervention for } \\
\text { evolving anatomic problems. }\end{array}$ \\
\hline $\begin{array}{l}\text { Labile saturations and } \\
\text { pulmonary blood flows }\end{array}$ & $\begin{array}{l}\text { Labile saturations and pulmonary blood flows, attributed } \\
\text { to variable pulmonary to systemic blood flow ratio on } \\
\text { PGE, improved with ductal stent. }\end{array}$ & $\begin{array}{l}\text { Patient may require repeated cardiac catheterizations to } \\
\text { maintain stability during wait for a donor heart; this } \\
\text { also mirrors our general experience with } \\
\text { single-ventricle hybrid circulations. }\end{array}$ \\
\hline
\end{tabular}

$\overline{L D H}$, Lactate dehydrogenase; $N E C$, necrotizing enterocolitis; $V A D$, ventricular assist device; $C T$, computed tomography; $A K I$, acute kidney injury; $P G E$, prostaglandin E.

holes were created with a 6-mm punch on the "basket" portion of the cannula. Purse-string sutures were placed on the right atrium, and this modified cannula was then placed and tunneled out from the right upper abdomen. The cannulas were then connected into the Thoratec PediMag through a 1/4-inch connector and tubing. The PediMag pump was started and ramped up to $2400 \mathrm{rpm}$, generating $1.4 \mathrm{~L} / \mathrm{min}$ of flow $\left(6.5 \mathrm{~L} / \mathrm{min} / \mathrm{m}^{2}\right)$, to achieve a central venous pressure of $5 \mathrm{~mm} \mathrm{Hg}$. The chest was closed primarily without impairing VAD flow.

\section{Postoperative Course}

Postoperatively, the speed was decreased to $2100 \mathrm{rpm}$ (flow of $1.1 \mathrm{~L} / \mathrm{min}$, or $5.2 \mathrm{~L} / \mathrm{min} / \mathrm{m}^{2}$ ), where it remained for the rest of his course (range, 0.4-1.5 L/min). Heparin was started after bleeding stopped and switched to enoxaparin sodium (anti-Xa level 0.6-1.0), aspirin $(20 \mathrm{mg} / \mathrm{kg})$, and clopidogrel $(0.8 \mathrm{mg} / \mathrm{kg})$. The patient was extubated on postoperative day (POD) 10. His atrial septum required stenting on POD 26 as a result of progressive restrictive physiology, and his patent ductus arteriosus was stented on POD 29 for labile saturations. Pedimacs-defined adverse and problems encountered are summarized in Table 1 . The patient gained weight despite being unable to tolerate enteral feeds consistently. After 4.5 months of support, he underwent a successful transplant. He was discharged home on posttransplant day 90 and is now doing well 6 months posttransplant.

\section{DISCUSSION}

In this report, we document our first successful use of the PediMag device to bridge to HT a neonate with HLHS and 
severe right ventricular dysfunction. Although the technique we used was similar to that described by the St Louis group, ${ }^{3}$ there are 3 notable differences. First, the arterial cannula was inserted into the pulmonary trunk, rather than a reconstructed neoaorta, where the coronary and carotid arteries were perfused retrograde through the ductus, which was kept patent by prostaglandins and later a stent. Second, we created additional holes on the atrial side of the Berlin Heart inflow cannula to ensure excellent venous drainage and pump flows, which are important for the volume-loaded physiology of patients with single-ventricle anatomy. This strategy resulted in excellent flows (as great as $1.5 \mathrm{~L} / \mathrm{min}$, or $7 \mathrm{~L} / \mathrm{min} / \mathrm{m}^{2}$ ) as the patient grew, and did not produce signs of obstruction or thrombus formation. The anastomosis was straightforward because of the purse-string suture technique used. Finally, we used Dacron polyester fabric rather than polytetrafluoroethylene for the interposition graft for the pulmonary artery anastomosis. Although Dacron polyester fabric is reported to have a lower long-term patency rate, we believed that its lower bleeding risk made it a superior option in this situation for short-term support.

Although there were several adverse events during support, we were fortunate to avoid any neurologic complications. We found this continuous-flow support configuration to be more effective in decompressing the single-ventricle heart than pulsatile flow ${ }^{4}$ (a $10-\mathrm{mL}$ Berlin
Heart pump running at 100 beats/min could deliver no more than $1 \mathrm{~L} / \mathrm{min}$ under optimal conditions), as we have shown previously in an ovine single-ventricle model. ${ }^{5}$ Most importantly, we were able to bridge the patient successfully to HT through a period of 4.5 months, which gives us hope that novel support strategies such as this will decrease the high mortality facing neonates with singleventricle physiology and heart failure.

We are grateful to the St Louis group and Drs Peter Weardon and Peter Maul for their advice regarding implantation and management of the PediMag device.

\section{References}

1. Almond CS, Singh TP, Gauvreau K, Piercey GE, Fynn-Thompson F, Rycus PT, et al. Extracorporeal membrane oxygenation for bridge to heart transplantation among children in the United States: analysis of data from the organ procurement and transplant network and extracorporeal life support organization registry. Circulation. 2011;123:2975-84.

2. Conway J, St Louis J, Morales DL, Law S, Tjossem C, Humpl T. Delineating survival outcomes in children $<10 \mathrm{~kg}$ bridged to transplant or recovery with the Berlin Heart EXCOR ventricular assist device. JACC Heart Fail. 2015;3: $70-7$

3. Gazit AZ, Petrucci O, Manning P, Shepard M, Baltagi S, Simpson K, et al. A novel surgical approach to mechanical circulatory support in univentricular infants. Ann Thorac Surg. 2017;104:1630-6.

4. Ren S, Li X, Wen J, Zhang W, Liu P. Systematic review of randomized controlled trials of different types of patch materials during carotid endarterectomy. PLoS One. 2013;8:e55050.

5. Fujii Y, Ferro G, Kagawa H, Centola L, Zhu L, Ferrier WT, et al. Is continuous flow superior to pulsatile flow in single ventricle mechanical support? Results from a large animal pilot study. ASAIO J. 2015;61:443-7. 